\title{
Statyba
}

\section{INVESTIGATIONS OF LOW-CEMENT CASTABLES WITH SHAMOTTE AGGREGATE}

\section{S. Goberis , L. Merlinskaja \& I. Pundienè}

To cite this article: S. Goberis , L. Merlinskaja \& I. Pundienè (1999) INVESTIGATIONS OF LOW-CEMENT CASTABLES WITH SHAMOTTE AGGREGATE, Statyba, 5:1, 32-35, DOI: 10.1080/13921525.1999.10531430

To link to this article: https://doi.org/10.1080/13921525.1999.10531430

$$
\text { 曲 Published online: } 26 \text { Jul } 2012 .
$$

Submit your article to this journal

III Article views: 93 


\title{
MAŽACEMENČIO KAITRAI ATSPARAUS BETONO SU ŠAMOTO UŽPILDU TYRIMAI
}

\author{
S. Goberis, L. Merlinskaja, I. Pundienè
}

\section{1. İvadas}

Daugelyje darbų, pavyzdžiui $[1,2,3]$, pateikiami kaitrai atsparaus betono su specialiai pagamintu šamoto užpildu (vandens igèris 3-5\% [4]) charakteristiku tyrimu duomenys. Užsienyje (Vokietija, Lenkija, Danija, Anglija) kaitrai atspariam betonui naudojamas tankus užpildas su didesniu $\mathrm{Al}_{2} \mathrm{O}_{3}$ (iki $45 \%$ ) kiekiu. Toks betonas būna tradicinès sudèties, kuriame cemento kiekis sudaro $15-25 \%$, ir mažacementis (3$5 \%$ cemento) su ịvairiais priedais. Tradicinio ir mažacemenčio betono charakteristikos pateiktos 1 lentelèje remiantis firmų gamintojų duomenimis.

Lentelès duomenys parodo pagrindini savybiy skirtumą tarp mažacemenčio ir tradicinio betono: po degimo aukštose temperatūrose pirmos grupès betono stipris gniuždant smarkiai padidèja, o antros grupés betonu - sumažèja, palyginti su stipriu po džiovinimo, 2-5 kartus. Didžiausiu stipriu gniuždant išsiskiria tradicinis betonas "Comprit-115" ir "Comprit-130", bet, išdegus $1000^{\circ} \mathrm{C}$ temperatūroje, jo stipris gniuždant sumažeja atitinkamai 5 ir 2 kartus, o mažacemenčio "Didurit" markès betono stipris po degimo daug didesnis nei po džiovinimo.

Atliktų tyrimų tikslas - gauti mažacementị naujos kartos (pagerintų charakteristikų) betoną naudojant šamoto, kuris geriau sugeria vandeni, užpildą. Lietuvoje specialūs šamoto užpildai negaminami, bet po šiluminiy agregatų remonto lieka daug šamoto laužo, kuri galima panaudoti naujai sukurtiems betonams, be to, tai padètu spręsti pramoniniu atlieku utilizavimo problemą. Kuriamo betono savybès buvo lyginamos su tradicinio ir mažacemenčio betono, pagaminto naudojant aukštos kokybẻs šamotą, savybèmis.

\section{Tyrimai ir rezultaty aptarimas}

Šiame darbe betono užpildui šamotas paruoštas iš jau naudotu gaminių, turintis $30-33 \% \mathrm{Al}_{2} \mathrm{O}_{3}$. Tokio užpildo vandens igeris daug didesnis ir siekia net 12$15 \%$. Be to, tyrimai parode, kad šamoto laužo užpildas yra nevienalytis: bandinių, išpjautų iš vienos gaminio

1 lentelè. Ivairiụ firmu gamintojų kaitrai atsparaus betono palyginamosios charakteristikos (tankinimo būdas - vibracija)

Table 1. The comparative properties of refractory castables manufactured by different companies (compaction method - vibration)

\begin{tabular}{|c|c|c|c|c|c|c|}
\hline \multirow{2}{*}{$\begin{array}{l}\text { Betono } \\
\text { markè }\end{array}$} & \multirow{2}{*}{$\begin{array}{c}\mathrm{Al}_{2} \mathrm{O}_{3} \\
\text { kiekis užpilde, \% }\end{array}$} & \multicolumn{3}{|c|}{ Stipris gniuždant $\mathrm{MPa}$, po } & \multirow{2}{*}{$\begin{array}{l}\text { Deformacija, } \\
\% \text { po degimo } \mathrm{T}\end{array}$} & \multirow{2}{*}{$\begin{array}{c}\text { Panaudojimo } \\
\text { temperatūra, }{ }^{\circ} \mathrm{C} \\
\end{array}$} \\
\hline & & kietejimo & džiovinimo & degimo & & \\
\hline \multicolumn{7}{|l|}{ Mažacementis } \\
\hline Didurit-135 [1] & 35 & - & 55 & $70(1000)$ & $\begin{array}{l}0,05(110) \\
0,2(1000)\end{array}$ & 1350 \\
\hline Didurit-140 [1] & 37 & $\overrightarrow{-}$ & 60 & $80(1000)$ & $\begin{array}{l}0,05(110) \\
0,2(1000)\end{array}$ & 1400 \\
\hline BN-135 [2] & 35 & 15 & 20 & $40(1350)$ & $1,0(1350))$ & 1350 \\
\hline \multicolumn{7}{|l|}{ Tradicinis } \\
\hline Comprit-115 [1] & 22 & - & 80 & $15(1000)$ & $\begin{array}{l}0,05(110) \\
0,2(1000)\end{array}$ & 1150 \\
\hline Comprit-130 [1] & 40 & - & 50 & $25(1000)$ & $\begin{array}{l}0,05(110) \\
0,1(1000)\end{array}$ & 1300 \\
\hline Plicast-18 [5] & 30 & - & 20 & $18(1100)$ & $\begin{array}{l}0,05(110) \\
0,4(1000) \\
\end{array}$ & 1280 \\
\hline Plicast-hydromix [5] & 35 & - & 22 & $14(1100)$ & $\begin{array}{c}0,05(110) \\
0,25(1000)\end{array}$ & 1320 \\
\hline BOS-125 [6] & 33 & 25 & - & $15(1250)$ & $1,5(1250$ & 1250 \\
\hline
\end{tabular}


nuolaužos, stipris gniuždant skiriasi 2-3 kartus. Tai nulemia betono, pagaminto su tokios kokybès užpildu, savybių skirtumus, palyginti su užsienio firmų betonais.

Buvo ištirtos trys kaitrai atsparaus betono sudètys. Nr. 1 ir Nr. 2 yra tradicinès sudeties betonas. I Nr. 1 sudètị ieina aliuminatinis cementas "Gorkal-40" (40\% $\mathrm{Al}_{2} \mathrm{O}_{3}$ ), i Nr. 2 sudèti - "Gorkal-70" (70\% $\mathrm{Al}_{2} \mathrm{O}_{3}$ ). Nr. 3 sudètis - mažacementis naujos kartos betonas ("Gorkal-70" - 5\%) su šamoto užpildu, $\mathrm{SiO}_{2}$ mikrodulkèmis bei deflokuliantu. Sudètys skiriasi ir užmaišomo vandens kiekiu: Nr. 1 - 17,7\%, Nr. 2 $14,2 \%$, Nr. 3-6,3\%. Masès konsistencija, kuri turi būti vienoda visoms sudetims, nustatoma pagal žinomą metodiką naudojant kratymo stalelị (flow table). Masė ruošiama 4 greičių ekscentrinèje maišyklèje "Maren". Buvo pagaminti bandiniai: $(70 \times 70 \times 70) \mathrm{mm}$ dydžio kubai ir $(40 \times 40 \times 160) \mathrm{mm}$ dydžio sijelès. Nustatytas bandinių tankis, stipris gniuždant po kietejjimo (3 paros), džiovinimo, degimo $500,800,1100,1300^{\circ} \mathrm{C}$ temperatūrose, ultragarso impulso sklidimo greitis po degimo $500,800,1100,1300^{\circ} \mathrm{C}$ temperatūrose, betono terminis patvarumas po ciklinio poveikio (degimas $800^{\circ} \mathrm{C}$ temperatūroje ir aušinimas vandenyje, šalto oro sroveje bei santykinio vertinimo metodu aušinant bandinius ant metalinio paviršiaus) [7], betono deformacija po degimo $800,1100,1300^{\circ} \mathrm{C}$ temperatūroje.

Pagrindinių betono savybių tyrimo rezultatai pateikti $1-4$ pav.

Betono tankio kitimas po ivairiu terminio apdorojimo etapu skirtingas priklausomai nuo sudeties (1 pav.).

Mažacemenčio betono tankis po kietejjimo šiek tiek didesnis nei tradicinio betono. Mažiausias tankis yra Nr. 1 sudèties betono, kuriame cemento ir vandens kiekis didžiausias. Džiovinant bandinius $105-110^{\circ} \mathrm{C}$ temperatūroje, visų tipų betono tankis kinta vienodai, t. y. prarandamas vienodas vandens kiekis. Po degimo aukštesnèse temperatūrose kreivių charakteris pasikeičia. Kadangi Nr. 3 sudètyje (mažacementis betonas) pirminis vandens kiekis buvo mažiausias, tai išdegus bandinius $800^{\circ} \mathrm{C}$ temperatūroje betono tankio kitimas sudarè $\sim 1 \%$, o tradiciniame betone $-7-8 \%$. Bandiniu degimas $1300^{\circ} \mathrm{C}$ temperatūroje skirtingai paveikè ju tankį: Nr. 1 ir Nr. 2 sudéčị tankis beveik nepakito, Nr. 3 sudèties padidejo 2\%, - tai turbūt susiję su bandinių deformacija (2 lent.).

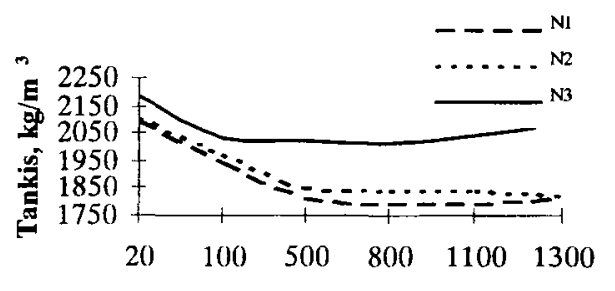

Temperatū ra, ${ }^{\circ} \mathrm{C}$

1 pav. Betono tankio priklausomybè nuo degimo temperatūros

Fig 1. Dependency of castable density on temperature of firing

Terminio apdorojimo itaka betono stipriui gniuždant atitinka minètus dèsningumus: $\mathrm{Nr} .1$ ir $\mathrm{Nr} .2$ sudètyse po džiovinimo ir degimo $800^{\circ} \mathrm{C}$ temperatūroje stipris gniuždant mažèja, Nr. 3 sudètyje smarkiai padideja ( 2 pav.).

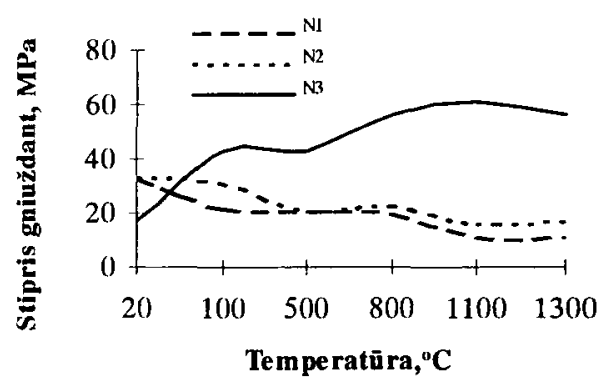

2 pav. Betono stiprio gniuždant priklausomybė nuo degimo temperatūros

Fig 2. Dependency of castable cold crushing strength on temperature of firing

Išryškèja ypatingas Nr. 3 sudèties betono pranašumas. Šios sudèties bandinyje cemento kiekis 4-5 kartus mažesnis nei tradiciniame betone ir stipris po kietejjimo perpus mažesnis, tačiau po džiovinimo Nr. 3 sudèties betono bandinys viršija Nr. 1 ir Nr. 2 sudèties bandiniu stipri gniuždant 1,5-2 kartus, o išdegus $800^{\circ} \mathrm{C}$ temperatūroje - beveik tris kartus. Tai priklauso nuo smulkiaporès betono struktūros susidarymo mažacemenčiame betone ir daug mažesnių destrukcijos procesų veikiant aukštai temperatürai. Išdegus Nr. 3 sudėties bandinius $1300^{\circ} \mathrm{C}$ temperatūroje, stipris šiek tiek sumažèja, tikriausiai, tai susiję su anortito $\left(\mathrm{CaO} \cdot \mathrm{Al}_{2} \mathrm{O}_{3} \cdot 2 \mathrm{SiO}_{2}\right)$ susidarymu dèl cemento ir $\mathrm{SiO}_{2}$ mikrodulkių tarpusavio sąveikos kietose fazèse [8]. Lyginant mūsų gautąsias betono (sudètys Nr. 1-3) stiprumo charakteristikas su kity firmų gamintoju 
duomenimis (1 lent.), matyti, kad stiprio gniuždant kitimas termiškai apdorojus tradicini betoną vienodas. Tas pats yra ir su mažacemenčiu betonu.

Ultragarso impulso sklidimo greitis bandiniuose priklauso nuo degimo temperatūros, kadangi nuo jos poveikio keičiasi betono struktūra ir dinaminis tamprumo modulis. Tyrimai parode, kad po degimo $800^{\circ} \mathrm{C}$ temperatūroje yra ultragarso sklidimo greičio koreliacija su betono stipriu gniuždant ( 3 pav.), o po degimo aukštesnese temperatūrose pastebimi palyginamuju rodikliu kreiviy nesutapimai, kurie galbūt atsiranda dèl naujų fazių, skatinančių ar stabdančių ultragarso sklidimą, susidarymo.

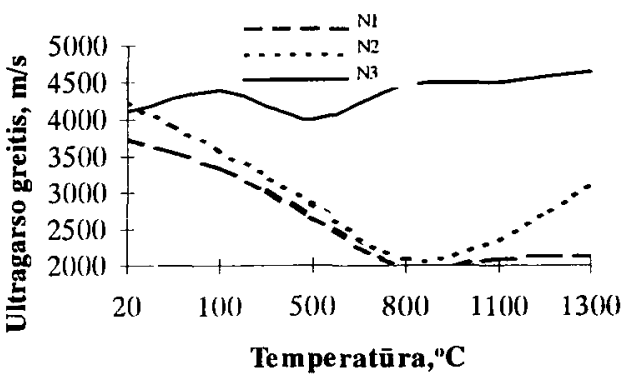

3 pav. Betono degimo temperatūros ịtaka ultragarso sklidimo greičiui

Fig 3. The influence of castable firing temperature on ultrasound velocity

Betono terminis patvarumas po 15 kaitinimo ir aušinimo oro sroveje ciklų, kuriuos išlaikẻ visi bandiniai, ivertinamas nustatant likutini stiprị gniuždant $\left(R_{g n .}^{l i k .}\right)$. Nr. 1 sudeties bandiniu likutinis stipris gniuždant sudare $92 \%$ bandinių, išdegtụ 1 kartą $800^{\circ} \mathrm{C}$ temperatūroje, stiprio gniuždant dydžio; Nr. 2 sudèties bandinių - 89\%; Nr. 3 sudèties - 98\%. Nustatant terminį patvarumą vandens ciklais, pastebèta, kad Nr. 1 ir Nr. 2 sudèčių bandiniai suiro atitinkamai po 10 ir 16 ciklụ, o Nr. 3 sudeties bandiniai nesuiro ir išsaugojo $43 \%$ pirminio stiprio po 15 ciklų.
Betono santykinio terminio patvarumo rezultatai (2 lent.) apskaičiuoti pagal bandinių - sijeliu stiprị lenkiant (4 pav.). Ju stipris buvo nustatytas 3 bandinius išdegus $800^{\circ} \mathrm{C}$ temperatūroje, kitus 6 bandinius 3 bei 7 ciklus kaitinant ir aušinant ant vandens šaldomo paviršiaus. Šie duomenys rodo, kad Nr. 1 ir Nr. 2 sudèči bandiniai po vienkartinio degimo turi 3-5 kartus mažesnị stiprị lenkiant nei Nr. 3 sudèties bandiniai.

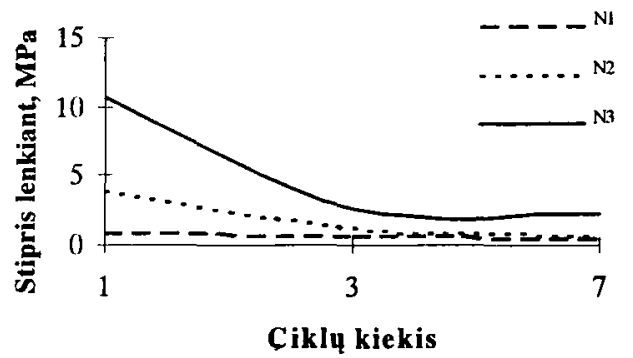

4 pav. Betono stiprio lenkiant priklausomybè nuo kaitinimo ir aušinimo ciklų skaičiaus

Fig 4. Dependency of castable bending strength on heatingcooling cycle number

Po 3 ir 7 aušinimo ciklu mažacemenčio betono bandiniai taip pat gerokai stipresni, bet ju stiprio kritimo kreivé staigesné, gal dèl tankesnès betono struktūros. Todèl mažacemenčio betono santykinio terminio patvarumo dydis yra lygiavertis tradicinio Nr. 2 betono dydžiui.

Aušinant bandinius oro ir vandens ciklais, pastebeta, kad mažacemenčio betono terminis patvarumas yra didesnis. Tai rodo ir $R_{\text {lenk. }}$. bei $R_{g n \text {. santykio }}$ rodiklis.

Iš antros lentelès duomeny matyti, kad mažacementis betonas, palyginti su tradiciniu betonu, skiriasi didesne deformacija. Rentgenografiniais tyrimais nustatyta, kad, veikiant aukštoms temperatūroms, amorfinè fazè šiame betone labai mažèja, matyt, dèl struktūros traukimosi kristalizacijos procese. Užsienio

2 lentelè. Papildomos ištirto betono charakteristikos

Table 2. Additional characteristics of castables

\begin{tabular}{|c|c|c|c|c|c|c|c|c|c|}
\hline \multirow{3}{*}{$\begin{array}{c}\text { Betono } \\
\text { sudéties } \\
\mathrm{Nr} .\end{array}$} & \multicolumn{5}{|c|}{ Terminis patvarumas } & \multicolumn{3}{|c|}{ Deformacija, $\%$ po ${ }^{\circ} \mathrm{C}$} & \multirow{3}{*}{$\begin{array}{c}R_{\text {lenk. }} 800^{\circ} \mathrm{C} / \\
R_{g n .} \\
800^{\circ} \mathrm{C}\end{array}$} \\
\hline & \multicolumn{2}{|c|}{ oro ciklai } & \multicolumn{2}{|c|}{ vandens ciklai } & \multirow[b]{2}{*}{$T_{\text {suntyk }}$} & \multirow[b]{2}{*}{800} & \multirow[b]{2}{*}{1100} & \multirow[b]{2}{*}{1300} & \\
\hline & $\begin{array}{l}\text { cikly } \\
\text { kiekis }\end{array}$ & $R_{g n .}^{l i k .} \mathrm{MPa}$ & $\begin{array}{c}\text { ciklu } \\
\text { kiekis }\end{array}$ & $R_{g n .}^{l i k \cdot} \mathrm{MPa}$ & & & & & \\
\hline 1 & 15 & 18,6 & 10 & - & 0,18 & $-0,28$ & - & - & 0,204 \\
\hline 2 & 20 & 20,2 & 16 & - & 0,28 & $-0,28$ & $-0,28$ & $-0,42$ & 0,175 \\
\hline 3 & 15 & 29,3 & 15 & 25,1 & 0,26 & $-0,42$ & $-0,50$ & $-1,13$ & 0,285 \\
\hline
\end{tabular}


firmy betono deformacijos rezultatai rodo panašią tendenciją, nors kai kuriuose literatüros šaltiniuose pabrèžiama, kad mažacemenčio betono deformacija mažesnè [2].

Ištirtos sudèties mažacementis betonas buvo pritaikytas firmos "Ipsen" krosnies, skirtos metalo gaminiams deginti, mufelio elementu gamybai. Krosnies eksploataciniai bandymai parodè, kad plonasieniai $(\sim 50 \mathrm{~mm})$ mufelio elementai atlaiko aukštą temperatūrą $\left(800^{\circ} \mathrm{C}\right)$ ir jos kitimą.

\section{Išvados}

Kaitrai atsparaus betono charakteristikų tyrimo rezultatai rodo galimybę gaminti mažacementị betoną naudojant šamoto laužo užpildą. Šio betono stiprumo charakteristikos šiek tiek mažesnis nei betono, kuriame naudojamas tankus specialiai paruoštas užpildas, tačiau veikiant aukštoms temperatūroms yra didesnis nei tradicinio betono ir atitinka šiluminių agregatų išklojimo reikalavimus.

Mažacemenčio betono terminis patvarumas didesnis nei tradicinio betono, bet didesne ir deformacija (traukimasis). Pirmoji priklausomybe paaiškinama mažacemenčio betono didesniu tankiu ir atsparumu lenkimui, o antroji - amorfinès fazès kristalizacija aukštose temperatūrose.

\section{Literatüra}

1. Didier. Wiesbaden, Didier-Werke AG, 1994.518 p.

2. J. Gradalska, M. Droždž, W. Wolek. Properties of LowCement Refractory Castables and Possibilities of their Use in Matallurgy // Proceedings of VI-th International Metallurgical Conference. Rudy Raciborskie, 1995, p. 56-57.

3. W. Stewart. Trends in monolithics // British Ceramic Transactions. Vol 93, Nr. 6, 1994, p. 252-254.

4. Ponholz. Maxhütte-Haidhaf, 1993.6 p.

5. Plibrico. Plibrico Ges.m.b.H. Wien, 1993. 40 p.

6. Refractory Traditional Castables and Prefabricate Products on their Base // Proceedings of VII-th International Metallurgical Conference. Ustron, 1997, p. $35-38$.

7. С. Ю. Гоберис, Л. И. Мерлинская. Новая методика определения жаростойких бетонов // Сб. трудов. Вып. 12. Вильнюс: ВНИИТеплоизоляция, 1979, c. $80-89$.
8. R. E. Fisher, L. P. Krietz. Bond Variation Effects on the Fracture Properties of Fireclay Castables // Unitecr Congress. Sept. 23-26. Aachen, 1991, p. 272-275.

\section{Įteikta 19981117}

\section{INVESTIGATIONS OF LOW-CEMENT CASTABLES WTTH SHAMOTTE AGGREGATE}

\section{S. Goberis, L. Merlinskaja, I. Pundienė}

Summary

The castables with low-cement and normal quantity cement in its composition physical and mechanical properties was investigated. Aggregates of recycled shamotte waste, which are characterised by high water absorption, were used for castables.

The results of influence of firing temperature on density and cold crushing strength for three series castables were determined (Fig 1 and 2). Thermal shock resistance, bending strength and deformations of the castables were investigated additionally (Table 2 and Fig 4).

The results of investigations showed the advantage of low-cement castables: better thermal shock resistance, higher cold crushing and bending strength after firing at high temperature.

The properties of developed low-cement and traditional castables produced with schamotte waste aggregates were compared with the data from German, Danish and Polish castables, a special quality shamotte aggregate was used (Table 1).

Low-cement castable based on shamotte waste aggregates were developed and used for producing "Ipsen" furnace lining items.

Stasys GOBERIS. Doctor. Head of Institute Termoizoliacija Laboratory. Institute Termoizoliacija, Linkmenu 28 , 2600 Vilnius, Lithuania.

A graduate of Ural Polytechnical Institute (1954, metallurgical engineer). Doctor (1966, thesis about technology of refractory concretes). Author of 217 papers, 23 inventions. Research interests: refractory materials, their application in furnaces.

Liudmila MERLINSKAJA. Assistant of Institute Termoizoliacija Laboratory. Institute Termoizoliacija, Linkmeny 28, 2600 Vilnius, Lithuania.

A graduate of Leningrad Technological Institute (1969, technologist). Co-author of 23 papers. Research interests: refractory materials, their application in furnaces.

Ina PUNDIENE. Doctoral student at Termoizoliacija Institute. Linkmenų 28, 2600 Vilnius, Lithuania.

A graduate of Riga Polytechnical Institute (1985, chemist-technologist). Co-author of 11 publications. Research interests: new refractory concretes and their technologies. 